\title{
MENINGKATKAN KEMAMPUAN GURU DALAM MENYUSUN PERANGKAT PEMBELAJARAN MELALUI SUPERVISI
}

\author{
Elin Yuliani \\ SMA Negeri 4 Tasikmalaya, Jl. Letnan Kolonel Re Jaelani, Cilembang, Kec. Cihideung, Tasikmalaya, Indonesia \\ email: elinyuliani@gmail.com
}

\begin{abstract}
Given the importance of preparing the syllabus and lesson plans by teachers, it is necessary to provide guidance for teachers so that the ability of teachers to develop syllabus and lesson plans can increase. The principal as the education leader in the school has a role as a supervisor in charge of fostering schools so that teachers can develop their abilities in the preparation of learning tools, namely syllabus and lesson plans. This research is School Action Research (PTS). The research subjects in this school action research were 56 teachers of SMA Negeri 4 Tasikmalaya. The object of research is the teacher's ability to develop learning tools. The number of cycles carried out was two, namely Cycle I and Cycle II. Based on the results of the School Action Research that has been carried out, it can be concluded that training in supervision activities can improve the ability of teachers in compiling the syllabus and lesson plans at SMAN 4 Tasikmalaya.
\end{abstract}

Keywords: Syllabus, lesson plans, supervision.

\begin{abstract}
ABSTRAK
Mengingat pentingnya menyusun silabus dan RPP oleh guru maka perlu diadakan pembinaan untuk para guru agar kemampuan guru dalam menyusun silabus dan RPP dapat meningkat. Kepala sekolah sebagai pimpinan pendidikan di sekolah memiliki peran sebagai supervisor yang bertugas membina sekolah agar dapat guru dapat mengembangkan kemampuannya dalam penyusunan perangkat pembelajaran yaitu silabus dan RPP. Penelitian ini merupakan Penelitian Tindakan Sekolah (PTS). Subjek penelitian pada penelitian tindakan sekolah ini adalah guru SMA Negeri 4 Tasikmalaya sebanyak 56 orang. Objek Penelitian adalah kemampuan guru dalam menyusun perangkat pembelajaran. Jumlah siklus yang dilaksanakan sebanyak dua yaitu Siklus I dan Siklus II. Berdasarkan hasil Penelitian Tindakan Sekolah yang telah dilaksanakan, maka dapat disimpulkan bahwa pelatihan dalam kegiatan supervise dapat meningkatkan kemampuan guru dalam menyusun silabus dan RPP di SMAN 4 Tasikmalaya.
\end{abstract}

Kata Kunci: Silabus, RPP, Supervisi.

Cara sitasi: Yuliani, E. (2021). Meningkatkan Kemampuan Guru dalam Menyusun Perangkat Pembelajaran Melalui Supervisi. J-KIP (Jurnal Keguruan dan IImu Pendidikan), 2 (3), 49-52. 


\section{PENDAHULUAN}

Perangkat pembelajaran adalah komponen yang harus disiapkan oleh guru sebelum melaksanakan pembelajaran. Dalam KBBI (2007), perangkat adalah alat atau perlengkapan, sedangkan pembelajaran adalah proses atau cara menjadikan orang belajar. Menurut Zuhdan et al., (2011) perangkat pembelajaran adalah alat atau perlengkapan untuk melaksanakan proses yang memungkinkan pendidik dan peserta didik melakukan kegiatan pembelajaran. Perangkat pembelajaran menjadi pegangan bagi guru dalam melaksanakan pembelajaran baik di kelas, laboratorium atau di luar kelas.

Dalam Permendikbud No. 65 Tahun 2013 tentang Standar Proses Pendidikan Dasar dan Menengah disebutkan bahwa penyusunan perangkat pembelajaran merupakan bagian dari perencanaan pembelajaran. Perencanaan pembelajaran dirancang dalam bentuk silabus dan RPP yang mengacu pada standar isi. Selain itu, dalam perencanaan pembelajaran juga dilakukan penyiapan media dan sumber belajar, perangkat penilaian, dan skenario pembelajaran.

Peraturan Menteri Pendidikan dan Kebudayaan Republik Indonesia No. 65 Tahun 2013 Tentang Standar Proses Pendidikan Dasar dan Menengah menjelaskan bahwa silabus merupakan acuan penyusunan kerangka pembelajaran untuk setiap bahan kajian mata pelajaran. Silabus dikembangkan berdasarkan Standar Kompetensi Lulusan dan Standar Isi untuk satuan pendidikan dasar dan menegah sesuai dengan pola pembelajaran pada setiap tahun ajaran tertentu. Silabus digunakan sebagai acuan dalam pengembangan rencana pelaksanaan pembelajaran.

Menurut Permendikbud No. 81A Tahun 2013 tentang Implementasi Kurikulum Pedoman Umum Pembelajaran, bahwa tahap pertama dalam pembelajaran menurut standar proses yaitu perencanaan pembelajaran yang diwujudkan dengan kegiatan penyusunan Rencana Pelaksanaan Pembelajaran (RPP). Selanjutnya dijelaskan bahwa RPP adalah rencana pembelajaran yang dikembangkan secara rinci dari suatu materi pokok atau tema tertentu yang mengacu pada silabus. RPP mencakup beberapa hal yaitu: (1) Data sekolah, mata pelajaran, dan kelas/ semester; (2) Materi Pokok; (3) Alokasi waktu; (4) Tujuan pembelajaran, KD dan indikator pencapaian kompetensi; (5) Materi pembelajaran; metode pembelajaran; (6) Media, alat dan sumber belajar / bahan ajar; (7) Langkah-langkah kegiatan pembelajaran; dan (7) Penilaian.

Mengingat pentingnya menyusun silabus dan RPP oleh guru maka perlu diadakan pembinaan untuk para guru agar kemampuan guru dalam menyusun silabus dan RPP dapat meningkat. Kepala sekolah sebagai pimpinan pendidikan di sekolah memiliki peran sebagai supervisor yang bertugas membina sekolah agar dapat mencapai tujuan pendidikan. Kepala sekolah dapat melakukan supervisi dengan cara pengawasan dan pengendalian untuk meningkatkan kinerja guru. Pengawasan dan pengendalian merupakan bentuk control agar kegiatan pendidikan di sekolah dapat terarah pada tujuan yang telah ditetapkan, tindakan ini juga dapat membantu guru dalam mengembangkan kemampuannya dalam penyusunan perangkat pembelajaran yaitu silabus dan RPP.

\section{METODE PENELITIAN}

Penelitian ini merupakan Penelitian Tindakan Sekolah (PTS). Lokasi Penelitian ini adalah di SMA Negeri 4 Tasikmalaya yang berlokasi di Jl. Letnan Kolonel Re Jaelani, Cilembang, Kec. Cihideung, Tasikmalaya, Jawa Barat 46123. Subjek penelitian pada penelitian tindakan sekolah ini adalah guru SMA Negeri 4 Tasikmalaya sebanyak 56 orang. Objek Penelitian adalah kemampuan guru dalam menyusun perangkat pembelajaran. Jumlah siklus yang dilaksanakan sebanyak dua yaitu Siklus I dan Siklus II. Masing-masing siklus terdiri dari perencanaan, pelaksanaan, pengamatan dan refleksi 


\section{HASIL PENELITIAN DAN PEMBAHASAN}

Pelaksanaan penelitian tindakan kelas dilakukan sebanyak 2 siklus dengan rangkuman hasil sebagai berikut:

\begin{tabular}{ccc} 
& \multicolumn{2}{c}{ Tabel 1. Rincian Hasil Tiap Siklus } \\
\cline { 2 - 3 } & $\begin{array}{c}\text { Hasil Pengisian Angket } \\
\text { Siklus I }\end{array}$ & $\begin{array}{c}\text { Hasil Pengisian Angket } \\
\text { Siklus II }\end{array}$ \\
\hline $\begin{array}{c}\text { Nilai rerata } \\
\text { Persentase } \\
\text { keberhasilan } \\
\text { Keputusan }\end{array}$ & 4,38 & 5,55 \\
\hline
\end{tabular}

Keputusan berdasarkan kriteria keberhasilan:

a. Siklus I dikatakan berhasil apabila 50\% peserta mencapai nilai 6 .

b. $\quad$ Siklus II dikatakan berhasil apabila $60 \%$ peserta mencapai nilai 6 .

Selanjutnya untuk penilaian observer diperoleh hasil sebagai berikut:

\begin{tabular}{ccc} 
& \multicolumn{2}{c}{ Tabel 2. Rincian Hasil Tiap Siklus } \\
\cline { 2 - 3 } & $\begin{array}{c}\text { Hasil Pengisian Angket } \\
\text { Observer Siklus I }\end{array}$ & $\begin{array}{c}\text { Hasil Pengisian Angket } \\
\text { Observer Siklus II }\end{array}$ \\
\hline $\begin{array}{c}\text { Nilai } \\
\text { Keputusan }\end{array}$ & 1 & 3 \\
\hline
\end{tabular}

a. Siklus I dikatakan berhasil apabila penilaian observer terhadap peserta mencapai nilai 2.

b. Siklus II dikatakan berhasil apabila penilaian observer terhadap peserta mencapai nilai 3.

Berdasarkan hasil penelitian maka diketahui bahwa pelatihan dalam rangka pelaksanaan kegiatan supervise dapat meningkatkan kemampuan guru dalam menyusun silabus dan RPP di SMAN 4 Tasikmalaya.

\section{Uraian Siklus I}

Kegiatan ini dimulai dengan mengurus perizinan penelitian, menyiapkan format lembar observasi dan menyusun angket. Kemudian pada pelaksanaan acara pelatihan dimulai dengan membuka acara pelatihan, melaksanakan pelatihan penyusunan silabus dan RPP pada guru SMA Negeri 4 Tasikmalaya yang berjumlah 56 orang, membuka sesi tanya jawab dengan peserta pelatihan dan meminta peserta untuk mempresentasikan tugasnya masing-masing. Terakhir adalah menutup kegiatan pelatihan. Selanjutnya hasil refleksi diperoleh peserta kurang kooperatif saat diminta presentasi dan saat tanya jawab peserta kurang aktif.

\section{Uraian Siklus II}

Siklus II dimulai dari menyiapkan format lembar observasi, menyusun angket dan menyiapkan materi dengan terlebih dahulu melakukan perbaikan dari materi sebelumnya. Pada saat pelaksanaan melakukan pembukaan untuk membuka acara pelatihan, melaksanakan pelatihan penyusunan silabus dan RPP pada guru SMA Negeri 4 Tasikmalaya yang berjumlah 56 orang, membuka sesi tanya jawab dengan peserta pelatihan, meminta peserta untuk share screen tampilan Google Classroom masing-masing, meminta peserta untuk mempresentasikan penguasaanya terhadap penyusunan silabus dan RPP, menyimpulkan kegiatan pelatihan tentang materi yang dibahas, dan menutup kegiatan pelatihan. Selama pelaksanaan 
siklus II tampak ada perubahan pada kegiatan yaitu guru-guru lebih aktif mengikuti kegiatan yang terlihat dari peserta kooperatif saat diminta untuk presentasi dan juga saat tanya jawab peserta lebih aktif.

Hasil penelitian ini sejalan dengan hasil penelitian Ali (2017) yakni melalui supervisi akademik dapat meningkatkan Kompetensi Guru dalam menyusun Rencana Pelaksanaa Pembelajaran di SMAN 1 Pinangsori Kabupaten Tapanuli Tengah. Begitu juga dengan hasil penelitian dari Yurnalis (2018) yaitu dengan supervisi klinis dpat meningkatkan kualitas perangkat pembelajaran yang dibuat guru di Sekolah Dasar Kecamatan Cerenti. Selanjutnya penelitian Dius (2016) yakni Hasil analisa revisi RPP pada siklus pertama memperlihatkan terjadinya peningkatan kualitas guru dalam penyusunan RPP.

\section{KESIMPULAN}

Berdasarkan hasil Penelitian Tindakan Sekolah yang telah dilaksanakan, maka dapat disimpulkan bahwa pelatihan dalam kegiatan supervise dapat meningkatkan kemampuan guru dalam menyusun silabus dan RPP di SMAN 4 Tasikmalaya. Berdasarkan hasil pengisian angket diperoleh bahwa siklus I belum terpenuhi karena belum mencapai kriteria keberhasilan yaitu hanya 20 dari 56 orang dengan besar prosentase hanya $36 \%$ peserta yang memperoleh nilai 6 dan sisanya sebanyak $64 \%$ peserta belum memperoleh nilai 6 . Rerata siklus 1 sebesar 4,38. Selanjutnya berdasarkan hasil observasi diperoleh bahwa siklus I nilainya sebesar 1 dan hal ini belum sesuai dengan kriteria keberhasilan. Berdasarkan hasil pengisian angket diperoleh bahwa siklus II telah terpenuhi karena telah mencapai kriteria keberhasilan yaitu 44 orang dari 56 orang dengan besar prosentase $79 \%$ peserta yang memperoleh nilai 6 dan sisanya sebanyak $21 \%$ peserta belum memperoleh nilai 6 hal ini telah sesuai dengan kriteria keberhasilan tindakan.

\section{REKOMENDASI}

Masih ada lagi perangkat pembelajaran lainnya yang belum terlatihkan Lembar Kerja Siswa (LKS).

\section{UCAPAN TERIMAKASIH}

Ucapan terimakasih penulis tujukan kepada pihak-pihak yang telah membantu dalam penelitian ini yaitu guru SMA N 4 Tasikmalaya.

\section{DAFTAR PUSTAKA}

Ali, M. (2017). Peningkatan Kemampuan Guru Dalam Menyusun Rencana Pelaksanaan Pembelajaran (Rpp) Melalui Supervisi Akademik. Jurnal IImu Pengetahuan Sosial, 3 (1).

Dius, E. (2016). Upaya Peningkatan Kompetensi Guru Dalam Menyusun Rpp Melalui Supervisi Akademik Pada Sd Binaan Di Kecamatan Sepauk Kabupaten Sintang. Jurnal Pendidikan Kewarganegaraan, $1(2)$.

KBBI. (2007). Kamus Besar Bahasa Indonesia Edisi Ketiga. Jakarta: Balai Pustaka.

Yurnalis. (2018). Upaya Meningkatkan Kemampuan Guru dalam Menyusun Perangkat Pembelajaran melalui Supervisi Klinis di Sekolah Binaan Kecamatan Cerenti. Jurnal Pajar (Pendidikan dan Pengajaran), 2 (4), 2614-1337.

Zuhdan, K.P., et al. (2011). Pengembangan Perangkat Pembelajaran Sains Terpadu Untuk Meningkatkan Kognitif, Keterampilan Proses, Kreativitas serta Menerapkan Konsep IImiah Peserta Didik SMP. Program Pascasarjana UNY. 